\title{
Controversies
}

\author{
Russell Knudsen, MBBS, FISHRS I Sydney, Australia I drknudsen@knudsen.com.au
}

\section{Losing Our Patients} where there was some control over advertising content in that "truth in advertising" regulations applied. "Fluff" was allowed (e.g., "we are the best clinic in the world," which only qualifies as exaggeration), but outright deception could be challenged.

The arrival of the internet has changed everything. Not only websites and optimising "Google searches," but also the arrival of social media where there is virtually no control over posted content. As a result, unscrupulous, dishonest advertising has flourished and non-physicians (i.e., businesspeople) have begun flocking into our marketplace. The result is that many "illegal" clinics (non-physicians illegally performing FUE transplants) in many countries have resulted in a price war that sees a race to the bottom in pricing. The advantage to patients with limited funds is clear. They are now more able to access a service previously beyond their budget. The problem is that it now seems to them to be a simple, common product.

Two recent emails from patients made me take notice. The first email said: "I am prepared to pay $\$ 3,000$ for 1,500 FUE grafts. Are you interested?" This is product shopping as clearly the price is the most important factor. The second email was more troubling: "Hi. I am a patient of yours from 5 years ago and am happy with the result of the transplant. I have lost more hair and I notice on the internet there are much cheaper options than you. I hope you would be charging a discount rate because, let's face it, it's not rocket science." So, it appears I have a happy patient who respects my work but doesn't respect the procedure?

The fact that FUE doesn't seem, to many patients, to be surgery has allowed this false impression to take hold. To its credit, the ISHRS has taken a stand against non-physician performed surgery and expects its members to follow the regulation. However, in our own practices, we now need to combat the dishonest and illegal marketing that the internet allows. In fact, it could be argued that Google reviews, for example, encourage dishonest content with fake reviews literally flooding the market but enhancing the credibility of the dishonest advertiser.
What are we to do in the face of this onslaught? Cosmetic medical tourism is only interested in performing the surgery as a one-time visit. Medical management and follow-up are usually nonexistent. Who amongst us has not had the experience of being asked to manage the follow-up of a "patient" (actually more accurately described as a "client") returning from an overseas surgery? Here in lies some of the answers to the problem. We have to encourage a personal dialogue and ongoing relationship with our prospective and actual patients. If you use consultants, make sure you actually introduce yourself to the patient at that first visit. Encourage a holistic approach to hair loss with proper discussion of the medical therapies that may be useful to the patient.

As well, we have to acknowledge that there is a segment of the patient marketplace that completely underestimates the complexity of the surgery and therefore expects to pay very little for the surgery. These were never our patients and we should not chase them using the offer of ever-lower pricing. If we don't respect our services, why should patients? They have no idea of the cost of provision of modern transplants with use of bio-enhanced solutions, etc. We cannot make it uneconomic for ourselves and survive long term in the field.

In Australia, it appears the number of patients having hair transplants is increasing but that most of the increase is being exported via medical tourism. This has to be partly expected via the democratisation of the internet marketplace, but it should not be a cause for panic by quality providers. There are many people who are interested in being educated about their options, both medical and surgical. We should continue to provide quality service at a fair price and to educate our patients (via website, social media, consultation, etc.) that we are not just providing a simple product but rather a comprehensive service. The care and skill of an experienced physician is crucial to the outcome and patient satisfaction. 